\title{
Family cohesion and health-related quality of life of children with type 1 diabetes: The mediating role of parental adjustment
}

Helena Moreira ${ }^{1}$, Roberta Frontini ${ }^{1}$, Monika Bullinger ${ }^{2}, \&$ Maria Cristina Canavarro $^{1}$

${ }^{1}$ Faculty of Psychology and Educational Sciences, University of Coimbra, Coimbra, Portugal

${ }^{2}$ Institute of Medical Psychology, University Medical Center, Hamburg-Eppendorf, Hamburg, Germany

\section{[post-print version]}

\section{Corresponding author:}

Moreira, $\mathrm{H}$.

Faculty of Psychology and Educational Sciences, University of Coimbra, Coimbra, Portugal

Faculdade de Psicologia e Ciências da Educação, Universidade de Coimbra, Rua do Colégio Novo, Apartado 6153, 3001-802 Coimbra, Portugal.

E-mail: hmoreira@fpce.uc.pt

Cite as:

Moreira, H., Frontini, R., Bullinger, M., \& Canavarro, M. C. (2014). Family cohesion and health-related quality of life of children with type 1 diabetes: The mediating role of parental adjustment. Journal of Child and Family Studies, 23(2), 347-359. doi:10.1007/s10826-013-9758-6

URL: http://link.springer.com/article/10.1007\%2Fs10826-013-9758-6 


\begin{abstract}
Despite the increasing number of studies on the health-related quality of life (HRQOL) of children with type 1 diabetes (T1D), little is known about the influence of family and parental factors on this outcome. This study aimed to explore whether family cohesion and children's HRQOL were connected through three indicators of parental psychological adjustment (parenting stress, depressive symptoms, and anxious symptoms) as well as whether these links varied according to the child's age. Levels of family cohesion, parenting stress, and depression/anxiety symptoms of parents of children with T1D and parents of healthy children were compared. The sample included 88 child-parent dyads composed of children/adolescents (8-18 years old) with T1D and one of their parents and 121 dyads composed of healthy children/adolescents and one of their parents. The parents completed self-report measures of family cohesion, parental stress, and emotional adjustment, and the children completed measures of HRQOL. Testing of the hypothesized moderated mediational model showed that higher HRQOL ratings in children were associated with higher levels of cohesion through lower levels of parental stress, regardless of the child's age. Parents of children with T1D perceived less cohesion and felt more anxiety and stress about parenting tasks compared to parents of healthy children. Our findings suggest that parents of children with T1D are at an increased risk of psychological maladjustment. Moreover, this study highlights the interrelation between family/parental functioning and child adjustment and makes an innovative contribution by identifying a mechanism that may account for the link between family and child variables.
\end{abstract}

Keywords: type 1 diabetes; health-related quality of life; family cohesion; parental adjustment; children; adolescents. 


\section{Introduction}

Recent years have witnessed increasing interest in assessing the health-related quality of life (HRQOL) of chronically ill children and adolescents (for brevity, the term children will be utilized to describe both children and adolescents) and children with type 1 diabetes (T1D; Peterson, Schmidt, Power, Bullinger, \& The DISABKIDS group, 2005; Varni, Seid, \& Kurtin, 1999). It is widely accepted that HRQOL is a key health outcome parameter that describes an individual's perception of the impact of a condition on his or her physical, mental, emotional, social, and behavioral well-being (Bullinger, Schmidt, Peterson, \& Ravens-Sieberer, 2006; Eiser \& Morse, 2001a; Peterson et al., 2005). Despite the increasing number of studies on this health outcome, little is known about the influence of family functioning on children's HRQOL. The present study explores the influence of family cohesion on the HRQOL of children with T1D and the mediating role of parental adjustment on this association.

T1D has been described as a "family disease" (Williams, Laffel, \& Hood, 2009), not only because of the central role that parents play in treatment management but also because of the interrelation of family functioning and child adjustment (Drotar, 1997; Kazak, 1997). Transactional (Sameroff, 1975) and family systems theories propose that the diagnosis of a chronic condition in a child affects the child's family (e.g., parents, siblings) and other systems (e.g., health care team). These systems can interact reciprocally and can influence and be influenced by the child (Kazak, Rourke, \& Navsaria, 2009). Thus, family functioning may affect the psychosocial adjustment of children, and children's adjustment can reciprocally influence the functioning of their families.

Several family variables (e.g., conflict, support, hostility, parenting styles) have been investigated among families with a child with T1D. In this study, we focus on family cohesion, which, in addition to conflict, has been considered a central dimension of family 
FAMILY AND HRQOL IN T1D

environment (Holmbeck, Coakley, Hommeyer, Shapera, \& Westhoven, 2002; Missotten, Luyckx, \& Seiffge-Krenke, 2012). This variable refers to appropriate, healthy, and positive interactions among family members (Field \& Duchoslav, 2009), and it describes the support that family members provide one another (Soliday, Kool, \& Lande, 2001). The impact of childhood T1D on family cohesion has previously been explored by comparing families who have a child with this chronic condition and families with a healthy child (e.g., Hamlett, Pellegrini, \& Katz, 1992; Missotten et al., 2012; Overstreet et al., 1995). The results are not consistent, as some studies show lower levels of cohesion among families with a child with T1D (Overstreet et al., 1995), whereas others report no differences between groups (Hamlett et al., 1992).

Previous studies have examined the influence of cohesion on children's health-related outcomes, particularly physical outcomes, and have found that more cohesive family environments predict better glycemic control and higher levels of adherence (Cohen, Lumley, Naar-King, Partridge, \& Cakan, 2004; Hauser et al., 1990). Nonetheless, compared to other family factors such as conflict or control, investigations of the role of family cohesion are scarce. Moreover, although the influence of family environment on the physical outcomes of children is relatively well established, little is known about the associations between family variables and psychosocial factors (children's behavioral problems, emotional adjustment, or HRQOL). For instance, it has been suggested that higher levels of conflict and lower levels of cohesion are associated with more externalizing (Hamlett et al., 1992) and internalizing behaviors (Missotten et al., 2012). Weissberg-Benchell et al. (2009) explored the role of several family variables on children's HRQOL and found that generic and disease-specific family factors explained $13 \%$ and $31 \%$ of HRQOL, respectively. In general, the literature suggests that structured, warmth and caring family environments may promote adherence to an adequate T1D regimen, better glycemic control (Anderson, 2004; Cohen et al., 2004; 
FAMILY AND HRQOL IN T1D

Hauser et al., 1990; Lewin et al., 2006), and better psychological adjustment (Hamlett et al., 1992). Aspects of family environment may also affect the psychological adjustment of parents. Blankfeld and Holahan (1996) found that higher levels of family support, as assessed by cohesion, conflict, and expressiveness, predicted fewer depressive symptoms among mothers of children with T1D.

Although associations between family functioning and diabetes-related outcomes are now better understood, the mechanisms or mediators that may account for these associations remain unclear. The psychological adjustment of parents is one possible avenue linking family environment and children's outcomes. Parents of children with T1D are exposed to a number of potential sources of stress because they must maintain a regular parenting role while caring for a child with a chronic condition that requires strict adherence to an intensive medical regimen (Streisand, Braniecki, Tercyak, \& Kazak, 2001; Streisand, Mckey, \& Herge, 2010). The complex and demanding treatment regimen encompasses a number of daily tasks, such as the frequent monitoring of blood glucose levels, insulin administration, and heightened attention to physical activity and dietary intake, particularly carbohydrates. Parents perform most of these tasks, especially during early childhood (Wysocki, Buckloh, \& Greco, 2009), and this responsibility can be burdensome, disrupting family relationships and increasing the likelihood of parental maladjustment. Parents of children with T1D, particularly mothers, have an increased risk of developing psychopathology symptoms, such as depressive symptoms (Driscoll et al., 2010; Jaser, Whittemore, Ambrosino, Lindemann, \& Grey, 2008; Kovaks, Obrosky, Goldston, \& Bonar, 1997; Williams et al., 2009), anxiety symptoms, or posttraumatic stress disorder (Horsch, McManus, Kennedy, \& Edge, 2007; Williams et al., 2009). Additionally, parents are likely to experience parenting stress related to caregiving and parental tasks (Mullins, Fuemmeler, Hoff, Chaney, Van Pelt, \& Ewing, 2004; Streisand, Swift, Wickmark, Chen, \& Holmes, 2005). 
FAMILY AND HRQOL IN T1D

More distressed parents are likely to have more distressed children (Cameron, Young, \& Wiebe, 2007; Eckshtain, Ellis, Kolmodin, \& Naar-King, 2010; Jaser et al., 2008; Kovaks et al., 1997). Kovaks et al. (1997) found that children diagnosed with T1D whose mothers presented significant depressive symptomatology had a likelihood of developing a depressive disorder that was 2.64 times higher than children whose mothers did not present this symptomatology. One of the few studies that investigated the association between parental emotional distress and children's HRQOL in the context of pediatric diabetes (Jaser et al., 2008) found that higher maternal depression was associated with poorer child HRQOL. Additional research has shown that higher parenting stress is associated not only with poorer psychological and physical well-being among parents of children with T1D (Streisand et al., 2005; Streisand et al., 2010) but also poorer child adjustment (Mullins et al., 2004).

This study has two main objectives. First, we aimed to compare levels of family cohesion, parenting stress, and parental emotional adjustment (depressive and anxious symptoms) in parents of children with T1D and parents of healthy children between the ages of 8 and 18. Lower levels of family cohesion and higher levels of parenting stress, depressive symptoms, and anxious symptoms were expected among parents of children with T1D. Second, we aimed to explore the indirect effect of family cohesion on children's HRQOL through three parental adjustment variables (parenting stress, anxiety, and depressive symptoms). It was expected that higher levels of family cohesion would be associated with a better HRQOL through lower levels of parenting stress and anxious/depressive symptomatology. In this mediational model, we hypothesized that the child's age would be a moderator because of expected developmental differences between children and adolescents. Figure 1 graphically depicts the hypothesized moderated mediation model.

Insert Figure 1 about here

\section{Methods}


FAMILY AND HRQOL IN T1D

\section{Participants}

The sample included 209 family dyads composed of a child/adolescent and one parent. Of these dyads, 88 included a child with T1D (G1), and 121 included a healthy child (G2). To be included in this study, G1 families had to meet the following inclusion criteria: (a) diagnosis of T1D, made by a qualified clinician, in a child between the ages of 8 and 18 years old at the time of recruitment; (b) no significant mental or medical condition other than T1D or developmental delays; and (c) having parents as the primary caregivers (i.e., parents must identify themselves as primarily responsible for the child's diabetes management). G2 children could not have any chronic health conditions, developmental delays, or severe psychiatric disorders and had to be between the ages of 8 and 18 years at the time of recruitment.

Table 1 presents the socio-demographic and clinical characteristics of the sample. G1 children $(56.8 \%$ girls) were between 8 and 18 years old $(M=13.22$ years; $S D=3.12)$, and the ages of their parents ( $92 \%$ mothers) ranged from 29 to 59 years $(M=42.94$ years; $S D=$ 5.55). The mean duration of diabetes was 70.04 months $(S D=46.95)$, and the mean glycosylated hemoglobin (HbA1c) was 7.59\% (SD=1.18). G2 children (55.4\% girls) were between 8 and 18 years old $(\mathrm{M}=12.68$ years; $S D=3.07)$, and their parents $(94.2 \%$ mothers $)$ were between 30 and 59 years old $(M=42.34$ years; $S D=5.52)$. No significant differences were found between G1 and G2 for youth and parent sociodemographic characteristics (see Table 1).

\section{Insert Table 1 about here}

\section{Procedure}

G1 families were recruited through the pediatric departments of two Portuguese public and urban hospitals between February and September 2012. The Ethics Committee and Direction Boards of both hospitals approved the study. Trained research assistants 
FAMILY AND HRQOL IN T1D

collected data before or after diabetes medical appointments. Participants completed the selfreport questionnaires in a consultation office provided for this purpose, and research assistants were available to provide assistance if necessary and to prevent the exchange of information between children and parents. Informed consent forms were obtained from the primary caregiver, and children were asked to assent to their own participation. Children who refused to participate were not included, even if their parents had previously consented.

A convenience sample of children with no medical conditions and their parents (G2) was collected in a Portuguese regular public school following authorization by the Direction Board. Teachers from several classes of children aged between 8 and 18 years old were contacted by the study researchers and instructed about the study aims and procedures. All of them agreed to participate and serve as intermediaries between the researchers and the families. The teachers gave parents a letter explaining the study and the informed consent. Parents who returned the informed consent form for their own and their child's participation received a packet with questionnaires to be completed at home and returned a week later. Parents were told that they could assist their children in understanding the items but could not influence their answers. A total of 253 children and their parents returned the questionnaires. Of these, 121 dyads with similar sociodemographic characteristics (parents and children's genders and ages, parents' marital and professional status and family income) to those of the clinical group were selected. Children with chronic health conditions and whose parents did not complete the questionnaires were excluded.

\section{Measures}

Children's HRQOL. In this study, we adopted a modular measurement strategy (Baars et al., 2005; Varni et al., 1999) that included a generic and a chronic generic measure of HRQOL. The generic measure allowed comparison between children with T1D and healthy children, and the chronic generic measure allowed a more comprehensive assessment 
FAMILY AND HRQOL IN T1D

of HRQOL within the clinical group. The generic HRQOL was assessed by the Portuguese self-report version of the KIDSCREEN-10 index (Gaspar \& Matos, 2008; Ravens-Sieberer et al., 2010), a 10-item questionnaire that assesses general subjective health and well-being ("Have you felt fit and well?"; "Have you had fun with your friends?") of healthy and chronically ill children between 8 and 18 years old. This measure is answered using a 5-point Likert scale that ranges from 1 (never; not at all) to 5 (always; extremely), with higher scores indicating better HRQOL. In the present sample, the Cronbach's alphas were .79 (G1) and $.77(\mathrm{G} 2)$.

The self-report version of the DISABKIDS Chronic Generic Module (Carona, Crespo, Silva, Lopes, Canavarro, \& Bullinger, 2012; The European DISABKIDS Group, 2006) was used to assess the impact of T1D on the quality of life of children aged 8 to 18 years. This instrument includes 37 items answered on a 5-point Likert scale that ranges from 1 (never) to 5 (always), with higher scores indicating better HRQOL. The items are assigned to six dimensions, which are associated with three domains. The Mental domain comprises the Independence (e.g., “Are you able to do things without your parents?") and Emotion (e.g., "Do you worry about your condition?") dimensions; the Physical domain comprises the Limitation (e.g., “Are you able to run and move as you like?”) and Treatment (e.g., "Does taking medication bother you?") dimensions; and the Social domain comprises the Social Inclusion (e.g., "Do you go out with your friends?”) and Social Exclusion (e.g., "Do you think that others stare at you?") domains. A general score for HRQOL can be computed (general HRQOL). This study examined the three domains and the general score. In this study, the Cronbach's alphas ranged from .72 (social domain) to .93 (total score).

Family cohesion. The Cohesion subscale of the Relationship dimension of the Portuguese version of the Family Environment Scale (FES; Moos \& Moos, 1986; Matos \& Fontaine, 1992) assesses individual perceptions of commitment to the family and the degree 
FAMILY AND HRQOL IN T1D

to which family members are helpful and supportive of one another. This subscale is composed of nine items (e.g., "Family members really help and support one another") answered on a 6-point Likert scale that ranges from 1 (completely disagree) to 6 (completely agree), with higher scores indicating a higher perception of cohesion within the family environment. In the present study, the Cronbach's alphas were .85 in both groups (G1 and G2).

Parents' emotional adjustment. The Portuguese version of the Hospital Anxiety and Depression Scale (Pais-Ribeiro et al., 2007; Zigmond \& Snaith, 1983) assesses current levels of depressive (e.g., "I feel cheerful") and anxious (e.g., "I feel tense or 'wound up"') symptomatology. This scale contains 14 items and uses a four-point scale that ranges from 0 (not at all; only occasionally) to 3 (most of the time; a great deal of the time), with higher scores indicating higher levels of symptomatology. In this sample, the Cronbach's alpha coefficients were .83 (G1) and .75 (G2) for anxiety and .74 (G1) and .71 (G2) for depression.

Parenting stress. The Parental Distress subscale of the Portuguese version of the Parenting Stress Index - Short Form (Abidin, 1995) was used to assess distress associated with the parental role. This subscale includes 12 items assessing several aspects associated with parenting distress, such as life restrictions due to the demands of child-rearing (e.g., "I feel trapped by my responsibilities as a parent”), answered on a 5-point Likert scale from 1 (completely disagree) to 5 (completely agree), with higher scores indicating higher levels of stress. In the present study, the Cronbach's alphas were .88 (G1) and .85 (G2).

Sociodemographic and clinical data. Sociodemographic and clinical information included parents' and children's ages and genders, parental marital status, professional status, family income, and education. Clinical information included the duration of T1D and values of glycosylated hemoglobin (HbA1c).

\section{Data Analyses}


FAMILY AND HRQOL IN T1D

Data analyses were conducted using the Statistical Package for the Social Sciences (SPSS, version 20.0; IBM SPSS, Chicago, IL). Moderated mediation models were tested through PROCESS (Hayes, 2012), a computational tool for path analysis-based moderation and mediation analyses, as well as a combination of both types of analyses in the so-called “conditional process model" (Hayes, 2012). Missing data were random and infrequent $(<5 \%)$ and were managed by simple group mean substitution. Demographic and clinical data were not substituted.

Descriptive statistics were computed for all socio-demographic, clinical, and study variables. Both chi-square tests and one-way ANOVAs were used to compare G1 and G2 on socio-demographic characteristics. The effects of the type of group (G1, G2) and age categories (children: 8 to 12 years old; adolescents: 13 to 18 years old) in family cohesion, parenting stress, and children's generic HRQOL were assessed with two-way ANOVAs. A two-way MANOVA, also with the type of group and age categories as independent variables, was performed on the two dimensions of parents' emotional adjustment (anxiety and depression). When a multivariate effect was found, subsequent ANOVAs were performed (one per dependent variable). For these analyses, two age groups were created based on the European DISABKIDS Group's (2006) approach: children (8 to 12 years old) and adolescents (13 to 18 years old).

Five moderated mediation models were estimated for G1 dyads, as depicted in Figure 1. In these models, parental perception of family cohesion was the independent variable; parenting stress, parental anxiety, and parental depressive symptomatology were mediators; child HRQOL (generic; chronic generic: general, social, mental, and physical) was the dependent variable; and child age was the moderator. A bootstrapping procedure was used to generate conditional indirect effects, and bias-corrected and accelerated confidence intervals (BCa CIs) were created with an indirect effect considered significant if zero was not 
FAMILY AND HRQOL IN T1D

contained within the lower and upper CIs. Prior to model estimation, products were mean centered to reduce multicollinearity, and the duration of T1D was entered as a covariate to control for its influence on the dependent variable (Tabachnik \& Fidell, 2007). Bootstrapping is a nonparametric resampling procedure that does not require the assumption of a normal distribution, and it demonstrates a higher power with reasonable control over the Type-I error rate through an appropriate control of confidence intervals (Preacher \& Hayes, 2008). Estimates of conditional effects at the $10^{\text {th }}, 25^{\text {th }}, 50^{\text {th }}, 75^{\text {th }}$, and $90^{\text {th }}$ percentiles of the moderator were generated. Following the recommendations of Hayes (2011), in the absence of a statistically significant interaction, a mediation model was estimated (i.e., without including the children's age as a moderator), and the unconditional indirect effects were analyzed.

Significance was set at the .05 level, and partial eta-squared $\left(\eta_{p}^{2}\right)$ provided the estimate of the effect size for the analyses of variance. Cohen's (1988) guidelines were used for describing the effect sizes of reported correlations (i.e., small for correlations around .10, medium for those near .30, and large for correlations at .50 or higher). Post hoc power calculations (G*Power; Faul, Erdfelder, Lang, \& Buchner, 2007) performed for analyses of variance, with a significance level of .05 and power of .80 , demonstrated that medium to large effects could be detected.

\section{Results}

\section{Group Differences and Correlations on Study Variables}

Table 2 presents the descriptive statistics of the study variables according to the type of group (G1, G2) and age categories (children, adolescents) and the group and age effects. A group effect was found for parental perception of family cohesion, $F(2,205)=8.84, p=.003$, $\eta_{\mathrm{p}}^{2}=.041$, with parents of children/adolescents with T1D reporting less cohesion than parents of healthy children/adolescents. No differences were found between parents of children and 


\section{FAMILY AND HRQOL IN T1D}

parents of adolescents, $F(2,205)=2.88, p=.09, \eta_{\mathrm{p}}^{2}=.014$, and no interaction was found between group and age categories, $F(2,205)=2.92, p=.09, \eta_{\mathrm{p}}^{2}=.014$.

Regarding parents' emotional adjustment, a multivariate group effect was found, Pillai's trace $=0.43, F(2,204)=4.61, p=.01, \eta_{\mathrm{p}}^{2}=.043$. The subsequent univariate analyses revealed a significant difference between $\mathrm{G} 1$ and $\mathrm{G} 2$ for anxious symptomatology, $F(1,205)$ $=8.74, p=.003, \eta_{\mathrm{p}}^{2}=.041$, with $\mathrm{G} 1$ parents reporting more anxiety than their $\mathrm{G} 2$ counterparts. No difference was found in depressive symptomatology, $F(2,205)=2.15, p=$ $.14, \eta_{\mathrm{p}}^{2}=.010$. The multivariate age effect, Pillai's trace $=0.16, F(2,204)=1.67, p=.19, \eta_{\mathrm{p}}^{2}$ $=.016$, and the multivariate interaction effect, Pillai's trace $=0.01, F(2,204)=1.24, p=.29$, $\eta_{\mathrm{p}}^{2}=.012$, were not significant.

For parenting stress, there were a significant group difference, $F(1,205)=3.50, p=$ $.05, \eta_{\mathrm{p}}^{2}=.017$, and an age difference, $F(1,205)=5.03, p=.03, \eta_{\mathrm{p}}^{2}=.024$. Parents of children/adolescents with T1D and parents of adolescents presented higher levels of parenting stress. The interaction between type of group and age was not significant, $F(1,205)$ $=0.10, p=.75, \eta_{\mathrm{p}}^{2}=.001$.

For children's generic HRQOL, no significant differences were found between G1 and $\mathrm{G} 2, F(1,204)=0.67, p=.41, \eta_{\mathrm{p}}^{2}=.003$. However, a significant difference was found between children and adolescents, $F(1,204)=50.00, p<.001, \eta_{\mathrm{p}}^{2}=.197$, with children reporting a better HRQOL. The interaction between type of group and age categories was not significant, $F(1,204)=1.02, p=.313, \eta_{\mathrm{p}}^{2}=.005$.

\section{Insert Table 2 about here}

Table 3 presents the Pearson correlations for the study variables for G1. Family cohesion was positively correlated with children's HRQOL (except with the physical domain) and negatively correlated with parental anxiety, depression, and parenting stress. Parental anxious and depressive symptoms and parenting stress were negatively correlated 
FAMILY AND HRQOL IN T1D

with child's general, social, mental, and physical HRQOL. Child age was negatively correlated with cohesion and with general and mental HRQOL. These correlations were mostly medium sized (Cohen, 1988).

\section{Insert Table 3 about here}

\section{The Indirect Effect of Family Cohesion on Children's HRQOL through Parental}

\section{Adjustment}

Examination of a multiple moderated mediation model (see Figure 1), one for each dimension of HRQOL, yielded no significant conditional indirect effects of family cohesion on child HRQOL through parenting stress, anxiety, and depression. That is, no significant interactions were found between children's age and family cohesion and between children's age and the three mediators. Because no conditional indirect effects were found, a simplified version of the initial model was tested. This latest version represented a multiple mediation model with no moderating variables. As presented in Table 4, the indirect effect of parents' perceptions of family cohesion on children's HRQOL was only significant through parenting stress. Specifically, a significant indirect effect through parenting stress was found for general HRQOL (point estimate $=2.10,95 \% \mathrm{BCa} C I=0.35 / 4.38$ ), social HRQOL, (point estimate $=5.70,95 \% \mathrm{BCa} C \mathrm{CI}=0.35 / 12.33$ ), and physical HRQOL (point estimate $=11.44$, $95 \% \mathrm{BCa} C \mathrm{I}=1.34 / 25.56)$. Higher levels of family cohesion were associated with lower levels of parenting stress, which were associated with better general, social, and physical HRQOL for children. The indirect effects for the generic and mental domains of HRQOL were not significant.

\section{Insert Table 4 about here}

\section{Discussion}

The main findings of this study are that parents of children with T1D perceived less cohesion in their family environment and felt more anxious and stressed about parenting 
FAMILY AND HRQOL IN T1D

tasks than parents of healthy children. In addition, higher levels of family cohesion were connected to better HRQOL for children through lower levels of parenting stress.

As expected, lower levels of family cohesion were found among families that had a child with T1D, regardless of the child's age. The intensive regimen treatment and the responsibility for T1D management may be overwhelming for parents, may disrupt family functioning and relationships within the family systems, and may decrease perceptions of proximity, connectedness, and support within the family. Similar results have been found in previous studies (Overstreet et al., 1995), but the literature is not consistent on this subject (Hamlett et al., 1992; Missotten et al., 2012). Although the age effect for family cohesion was only marginally significant and the interaction (age x group) effect did not reach statistical significance, it is worthwhile to note that among families with a child with T1D, a moderate and significant correlation between cohesion and child's age was found. The absence of a significant difference in the one-way ANOVA may have been due to the dichotomization of age, which may have led to a loss of statistical power and information and, therefore, to a failure to detect group differences (MacCallum, Zhang, Preacher, \& Rucker, 2002). When examining only families with a child with $\mathrm{T} 1 \mathrm{D}$, a negative correlation was found, indicating that as age increases, parents' perceptions of cohesion decrease, which is in accordance with previous studies (Field \& Duchoslav, 2009; Northam, Anderson, Adler; Werther, \& Warne, 1996). One of the main normative tasks of adolescence is independence from parents, a process that likely requires several readjustments within the family and may disturbs family functioning. In the context of this chronic condition, this normative disruption might be accompanied by the shift in responsibility for diabetes care that begins to be gradually transferred from the parents to the adolescent (Anderson, Ho, Brackett, \& Laffel, 1997). As a child grows older, a delicate balance between autonomy and parental involvement in T1D management is required to maintain adequate family adjustment. Therefore, it is possible that 
FAMILY AND HRQOL IN T1D

these normative changes affect the functioning of the family system and contribute to decreased perceptions of cohesion.

In line with our hypothesis, higher levels of anxiety and parenting stress were found among parents of children with T1D. Previous studies have consistently shown that parents of chronically ill children, specifically those diagnosed with diabetes, are at a greater risk of developing mental health problems (Driscoll et al., 2010; Kovaks et al., 1997). Caring for a child with this chronic condition may be highly challenging and distressing for parents because they not only have to deal with the demands of parenting, but also have to deal with the particular challenges of parenting a child with a chronic condition. For instance, parents take considerable responsibility for the management of T1D treatment. This process includes daily insulin administration, blood glucose monitoring four to six times a day, attention to dietary intake and physical activity, prevention of and intervention for hyperglycemia or hypoglycemia, and regular visits to medical appointments. This time-consuming and complex treatment regimen may lead to higher levels of anxiety and more difficulty in managing parenting tasks than that experienced by parents of healthy children. Moreover, increased levels of anxiety and parenting stress might also be associated with a myriad of other issues, such as frequent concerns about the child's future, long-term medical complications, financial issues, time demands, and disease management at school.

Contrary to our expectations and the findings of previous studies that reported elevated levels of depression (Horsch et al., 2007; Jaser et al., 2008), no group differences were found for depressive symptoms. Depression is closely associated with a perception or experience of loss or self-devaluation, whereas anxiety is connected to an experience or perception of threat or danger (Beck, Emery, \& Greenberg, 1985). In fact, parents may perceive a pediatric chronic health condition such as T1D as a threat to the health and wellbeing of the child, which may conduct to heightened anxiety. Moreover, T1D is 


\section{FAMILY AND HRQOL IN T1D}

characterized by a certain degree of unpredictability because episodes of hypoglycemia (extremely low blood glucose levels) may suddenly occur and result in severe complications if left untreated. This unpredictability, coupled with the complexity of the treatment regimen, can contribute to high levels of parental anxiety rather than increased levels of depressive symptoms.

No age differences were found in the levels of anxiety or depression, and the correlations between age and these variables were not significant. Nevertheless, we found that parents of adolescents (13-18 years) reported significantly more parenting stress than parents of children (8-12 years). This difference is independent of the type of group and is most likely associated with the normative changes that accompany the transition to adolescence, when youth gain independence from parents and become more autonomous. This developmental period is marked by important challenges and transformations within the parent-youth dyad, and some level of parenting stress can be expected (Small, Eastman, \& Cornelius, 1988).

Partially corroborating our hypothesis, we found that family cohesion was linked to the child's HRQOL via parenting stress in families of children and adolescents. We initially proposed a moderated mediational model in which child age served as the moderator due to the potential influence of the developmental stage of children on their own and their families' functioning. However, the proposed model was not moderated by child age, which suggests that the associations among the tested variables occur regardless of child age.

As expected, a cohesive family environment seems to help parents feel less distressed by the demands of the disease. Despite the remarkably limited research on the effects of family relationships on parental adjustment in the context of pediatric chronic conditions, some studies have found similar results (Blankfeld \& Holahan, 1996). As observed, higher levels of family cohesion were related to lower levels of depressive and anxious symptoms 


\section{FAMILY AND HRQOL IN T1D}

and parenting stress. This finding suggests that when family members support each other and family interactions are positive, the challenges associated with parenting a child with a chronic condition may be perceived as less demanding and burdensome, protecting the parents against psychological maladjustment. Positive social relationships are widely acknowledged as adaptive resources that may help individuals cope with stressful life situations and maintain adaptive functioning (Coyne \& Downey, 1991; Schwarzer, \& Leppin, 1991). Parents who live in a cohesive environment may receive more instrumental and emotional support (e.g., assistance with daily tasks, affection and concern from others), which may help them to better adjust to the daily demands of this chronic condition. Conversely, given the cross-sectional design of the study, the inverse relationship between cohesion and parental adjustment may also be conceivable. As such, more distressed parents may build less cohesive family environments. It may be that parental emotional distress and parenting stress contribute to less gratifying interactions among family members, increased conflict or difficulties in communicating effectively about diabetes or other issues (Williams et al., 2009), which may lead to a lower perception of support and cohesion among family members.

Regarding the paths between the three indicators of parental adjustment and children's HRQOL, we found that only higher levels of parenting stress were related to poorer children's HRQOL, which corroborates studies illustrating the significant impact of parenting stress on children's outcomes (e.g., Streisand et al., 2005; Streisand et al., 2010). A more distressed parent due to his/her functioning in the parental role may have more dysfunctional interactions with the child (Abidin, 1995), which can negatively influence the child's HRQOL. Given the cross-sectional design of the study, it is also possible that the child's HRQOL influences parental adjustment, particularly their parenting stress. Parents of children with more psychosocial difficulties can face more challenging caregiving tasks and 
FAMILY AND HRQOL IN T1D

feel more concerned with the child's health and well-being. As a result, they may feel more distressed with the childrearing and more stressed when interacting with the child than parents of children with better quality of life outcomes.

Additionally, it is important to note that differences in strengths of associations between family cohesion and the three parental adjustment indicators and between these indicators and children's HRQOL may be explained by the fact that HRQOL was selfreported by children and the independent and mediator variables were self-reported by parents. Therefore, it would be expected that associations between cohesion and parental adjustment would be stronger than associations between parental adjustment and children's HRQOL.

With regard to the mediational pathway, we found that parents who perceive their family relationships as supportive, positive, and caring are likely to feel less distressed by caregiving tasks, which is associated with a better general, physical, and social HRQOL of children. These results are in accordance with previous studies on other pediatric chronic conditions that have shown that a cohesive family protects the child against poor outcomes (Burke, Neigut, Kocoshis, Chandra, \& Sauer, 1994; Soliday et al., 2001), although these studies did not elucidate the mechanisms that may account for this relation. Contrary to our expectations, anxious and depressive symptoms did not mediate the link between cohesion and HRQOL. Distress that is directly related to the caregiving role seems to be more influential in the child's adjustment than parents' symptoms of individual psychological adjustment. A possible explanation is that parents who are highly distressed by parenting tasks may be hypervigilant to diabetes treatment and may engage in constant monitoring behaviors (Cunningham, Vesco, Dolan, \& Hood, 2011) that may have a detrimental effect on the child's HRQOL. Similarly, a distressed parent may adopt more ineffective parenting practices, which may negatively impact the child's outcomes. According to Abidin's (1995) 


\section{FAMILY AND HRQOL IN T1D}

parenting stress model, the links between parenting stress and child outcomes are mediated by parenting behaviors. Although the examination of this hypothesis is beyond the scope of this study, future studies should investigate whether the association between parenting stress and child's HRQOL is mediated by specific parenting styles.

Interestingly, contrary to our hypothesis, the mediation model did not apply to generic and mental HRQOL. Generic HRQOL was assessed by the KIDSCREEN index, which is a generic instrument that allows the assessment and comparison of HRQOL between healthy children and children with a chronic condition. However, this instrument does not allow a comprehensive assessment of children's HRQOL, particularly in the context of a chronic condition. When compared with DISABKIDS, this instrument is not as sensitive to aspects associated with a child's condition or treatment, which may partially explain the absence of a significant indirect effect and significant differences between the HRQOL of children with T1D and no medical condition. DISABKIDS, most likely because of its greater specificity and adequacy to assess the HRQOL of children with a chronic condition, was able to detect the hypothesized indirect effect in all domains and for the total score, with the exception of the mental domain. This result seems to suggest that dimensions of HRQOL that are more external, such as the social (e.g., stigma, feeling left out) and physical (e.g., perceived impact of taking insulin, difficulty sleeping) domains, are more easily disrupted by parenting stress than the more internal mental domain. Future studies should examine other factors that may be influential for mental HRQOL.

The cross-sectional design is the primary limitation of this study. Adjustment to a chronic condition is an ongoing dynamic process rather than a static outcome (Rentinck, Ketelaar, Jongman, \& Gorter, 2006), which may be better understood by using a longitudinal design. Furthermore, cross-sectional studies do not allow causal inferences because the observed associations among the variables can be bidirectional. For instance, a child's better 
FAMILY AND HRQOL IN T1D

HRQOL may predict higher levels of family cohesion. Future longitudinal studies are needed to explore the dynamic process of adjustment and to determine the direction of associations over time. Second, although we intended to recruit primary caregivers (regardless of their gender), $92 \%(\mathrm{G} 1)$ and $94.2 \%(\mathrm{G} 2)$ of the caregivers were mothers. Although this disproportion between maternal and paternal participation is common in pediatric research, it would be important to increase the number of fathers and to assess role differences. Third, our sample representativeness may be questioned because parents were recruited from a convenience sample of only two major public hospitals in the central region of Portugal. Nevertheless, the sample's sociodemographic characteristics (family income, professional status, and education) are similar to Portuguese national levels. Fourth, while children with T1D and their parents were assessed in a clinical context, with the presence of research assistants, healthy children and their parents completed the self-reported measures at home. These different sample collection procedures may also account for group differences in the study variables. Future studies should guarantee similar procedures (e.g., healthy children and their parents could complete the self-report measures in the classroom with the presence of a research assistant).

Despite these limitations, the current study demonstrated a number of strengths. This research focused on family and child variables that are relevant in this scientific domain but whose associations have rarely been investigated. To the best of our knowledge, this investigation is the first study to explore this mediational hypothesis, highlighting important links between family, parental, and child variables. The majority of studies have focused on direct relations between family functioning and physical outcomes, primarily metabolic control. Research on the links between family factors and the psychosocial outcomes of children with T1D as well as on the mechanisms accounting for these relations is remarkably limited. Additional significant strengths of this study include methodological choices that 


\section{FAMILY AND HRQOL IN T1D}

were made to overcome important limitations in previous research. First, the children's HRQOL was assessed through their self-reports rather than through the traditional proxy reports of parents. Research has emphasized the adequacy, utility, and relevance of children's self-reports (Eiser \& Morse, 2001b) because of the subjective nature of quality of life, although many studies continue to rely solely on parental reports. Second, the developmental differences between children and adolescents were explicitly considered by analyzing children and adolescents separately in the group comparison analyses and examining the moderating role of child's age in the mediational models. Most studies analyze children and adolescents as a single group and ignore any differences that may occur as a consequence of the different characteristics of each developmental stage. Third, the use of an adequate control group composed of dyads of a parent and a healthy child is an important aspect of this study that has not been considered in most studies.

This study has scientific and practical implications. Taken together, the results suggest that this chronic health condition may be considered a "family disease" (Williams et al., 2009) that affects not only children but also their parents. Additionally, our findings highlight the interrelation of child and family adjustment (Drotar, 1997; Kazak, 1997) and show that family cohesion and parental adjustment is associated with children's HRQOL. Addressing caregivers' psychological distress in family-based interventions seems to be essential to promote better HRQOL among children and adolescents with T1D. Rather than an exclusive focus on children, interventions should include the family, or at least the main caregiver. These interventions should promote strategies to improve positive family communication patterns and mutual support that could subsequently improve cohesion within the family and diminish parenting stress. Additionally, individual interventions may be necessary for parents to provide strategies aimed at reducing parenting stress and psychopathological symptoms. Health care professionals should be aware of the increased 
risk of parental maladjustment in the context of this pediatric condition and should refer the parent to a mental health specialist if needed or provide specific parent-centered interventions. Overall, this study supports family-oriented pediatrics, as recommended by the American Academy of Pediatrics Task Force on Family (Schor, 2003). Given the key role of the family to children's health and well-being, the screening, assessment, and referral of parents who exhibit psychosocial difficulties, should be an integral part of pediatrics. 


\section{References}

Abidin, R. R. (1995). Parenting Stress Index: Professional Manual (3rd ed.). Odessa, FL: Psychological Assessment Resources, Inc.

Anderson, B. (2004). Family conflict and diabetes management in youth: Clinical lessons from child development and diabetes research. Diabetes Spectrum, 17, 22-26. doi: 10.2337/diaspect.17.1.22

Anderson, B., Ho, J., Brackett, J., Finkelstein, D., \& Laffel, L. (1997). Parental involvement in diabetes management tasks: Relationships to blood glucose monitoring adherence and metabolic control in young adolescents with insulin-dependent diabetes mellitus. The Journal of Pediatrics, 130, 257-265.

Baars, R., Atherton, C., Koopman, H., Bullinger, M., Power, M., \& the DISABKIDS group (2005). The European DISABKIDS project: Development of seven condition-specific modules to measure health related quality of life in children and adolescents. Health and Quality of Life Outcomes, 3, 70. doi: 10.1186/1477-7525-3-70

Beck, A. T., Emery, G., \& Greenberg, R. L. (1985). Anxiety disorders and phobias: A cognitive perspective. New York: Basic Books.

Blankfeld, D. \& Holahan, C. (1996). Family support, coping strategies, and depressive symptoms among mothers of children with diabetes. Journal of Family Psychology, 10, 173-179.

Bullinger, M., Schmidt, S., Petersen, C., \& Ravens-Sieberer, U. (2006). Quality of life: Evaluation criteria for children with chronic conditions in medical care. Journal of Public Health, 14, 343-355. doi: 10.1007/s10389-006-0066-0

Burke, P., Neigut, D., Kocoshis, S., Chandra, R., \& Sauer, J. (1994). Correlates of depression in new onset pediatric inflammatory bowel disease. Child Psychiatry and Human Development, 4, 275-283. doi: 10.1007/BF02353203 
FAMILY AND HRQOL IN T1D

Cameron, L., Young, M., \& Wiebe, D. (2007). Maternal trait anxiety and diabetes control in adolescence with type 1 diabetes. Journal of Pediatric Psychology, 32, 733-744. doi: 10.1093/jpepsy/js1053

Carona, C., Crespo, C., Silva, N., Lopes, A. F., Canavarro, M. C., \& Bullinger, M. (2012). Examining a developmental approach to health-related quality of life assessment: Psychometric analysis of DISABKIDS generic module in a Portuguese sample. Vulnerable Children and Youth Studies. Advance online publication. doi: $10.1080 / 17450128.2012 .736647$

Cohen, J. (1988). Statistical power analysis for the behavioral sciences. Hillsdale, NJ: Erlbaum.

Cohen, D., Lumley, M., Naar-King, S., Partridge, T., \& Cakan, N. (2004). Child behavior problems and family functioning as predictors of adherence and glycemic control in economically disadvantaged children with Type 1 Diabetes: A prospective study. Journal of Pediatric Psychology, 29, 171-184. doi: 10.1093/jpepsy/jsh019

Coyne, J. C. \& Downey, G. (1992). Social factors and psychopathology: Stress, social support, and coping processes. Annual Review of Psychology, 42, 401-425.

Cunningham, N., Vesco, A., Dolan, L., \& Hood, K. (2011). From caregiver psychological distress to adolescent glycemic control: The mediating role of perceived burden around diabetes management. Journal of Pediatric Psychology, 36, 196-205. doi: 10.1093/jpepsy/jsq071

Driscoll, K., Johnson, S., Barker, D., Quittner, A., Deeb, L., Geller, D., ... Silverstein, J. (2010). Risk factors associated with depressive symptoms in caregivers of children with type 1 diabetes or cystic fibrosis. Journal of Pediatric Psychology, 35, 814-822. doi: 10.1093/jpepsy/jsp138 
FAMILY AND HRQOL IN T1D

Drotar, D. (1997). Relating parent and family functioning to the psychological adjustment of children with chronic health conditions: What have we learned? What do we need to know? Journal of Pediatric Psychology, 22, 149-165. doi: 10.1093/jpepsy/22.2.149

Eckshtain, D., Ellis, D., Kolmodin, K., \& Naar-King, S. (2010). The effects of parental depression and parenting practices on depressive symptoms and metabolic control in urban youth with insulin dependent diabetes. Journal of Pediatric Psychology, 35, 426435. doi: doi: 10.1093/jpepsy/jsp068

Eiser, C., \& Morse, R. (2001a). Can parents rate their child's health-related quality of life? Results of a systematic review. Quality of Life Research, 10, 347-357. doi: 10.1023/A:1012253723272

Eiser, C., \& Morse, R. (2001b). The measurement of quality of life in children: Past and future perspectives. Developmental and Behavioral Pediatrics, 22, 248-256.

Faul, F., Erdfelder, E., Lang, A.-G., \& Buchner, A. (2007). G*Power 3: A flexible statistical power analysis program for the social, behavioural, and biomedical sciences. Behaviour Research Methods, 39, 175-191. doi:10.3758/BF03193146

Field, C. \& Duchoslav, R. (2009). Family influence on adolescent treatment outcomes. In W. T. O’Donohue \& L. W. Tolle (eds.), Behavioral approaches to chronic disease in adolescence (pp. 47-54). New York: Springer.

Gaspar, T., \& Matos, M.G. (Eds.) (2008). Qualidade de vida em crianças e adolescentes: Versão portuguesa dos instrumentos KIDSCREEN-52 [Quality of life in children and adolescents: Portuguese version of the instruments KIDSCREEN-52]. Cruz Quebrada: Aventura Social e Saúde.

Hamlett, K., Pellegrini, D., \& Katz, K. (1992). Childhood chronic illness as a family stressor. Journal of Pediatric Psychology, 17, 33-47. doi: 10.1093/jpepsy/17.1.33 
FAMILY AND HRQOL IN T1D

Hauser, S., Jacobson, A., Lavori, P., Wolfsdorf, J., Herskowitz, R., Milley, J., ... Stein, J. (1990). Adherence among children and adolescents with insulin-dependent diabetes mellitus over a four-year longitudinal follow-up: II. Immediate and long-term linkages with the family milieu. Journal of Pediatric Psychology, 15, 527-542. doi: 10.1093/jpepsy/15.4.527

Hayes, A. F. (2011). SPSS MODMED macro syntax reference. Retrieved from http://www.afhayes.com/public/modmed.pdf.

Hayes, A. F. (2012). PROCESS: A versatile computational tool for observed variable mediation, moderation, and conditional process modeling [White paper]. Retrieved from http://www.afhayes.com/ public/process2012.pdf

Holmbeck, G., Coakley, R., Hommeyer, J., Shapera, W., \& Westhoven, V. (2002). Observed and perceived dyadic and systemic functioning in families of preadolescents with spina bifida. Journal of Pediatric Psychology, 27, 177-189. doi: 10.1093/jpepsy/27.2.177

Horsch, A., McManus, F., Kennedy, P., \& Edge, J. (2007). Anxiety, depressive, and posttraumatic stress symptoms in mothers of children with type 1 diabetes. Journal of Traumatic Stress, 20, 881-891. doi: 10.1002/jts.20247

Jaser, S., Whittemore, R., Ambrosino, J., Lindemann, E., \& Grey, M. (2008). Mediators of depressive symptoms in children with type 1 diabetes and their mothers. Journal of Pediatric Psychology, 33, 509-519. doi:10.1093/jpepsy/jsm104

Kazak, A. (1997). A contextual family/systems approach to pediatric psychology: Introduction to the special issue. Journal of Pediatric Psychology, 22, 141-148. doi: 10.1093/jpepsy/22.2.141

Kazak, A., Rourke, M., \& Navsaria, N. (2009). Families and other systems in pediatric psychology. In M. C. Roberts, \& R. G. Steele (Eds.), Handbook of pediatric psychology ( $4^{\text {th }}$ ed, pp. 656-671). New York: The Guilford Press. 
FAMILY AND HRQOL IN T1D

Kovaks, M., Obrosky, D., Goldston, D., \& Bonar, L. (1997). Psychiatric disorders in youths with IDDM: Rates and risk factors. Diabetes Care, 20, 36-44. doi:

$10.2337 /$ diacare.20.1.36

Lewin, A., Heidgerken, A., Geffken, G., Williams, L., Storch, E., Gelfand, K., \& Silverstein, J. (2006). The relation between family factors and metabolic control: The role of diabetes adherence. Journal of Pediatric Psychology, 31, 174-183. doi: 10.1093/jpepsy/jsj004

MacCallum, R. C., Zhang, S., Preacher, K. J., \& Rucker, D. D. (2002). On the practice of dichotomization of quantitative variables. Psychological Methods, 7, 19-40.

Matos, P.M., \& Fontaine, M. (1992). Family Environment Scale. Adaptação portuguesa [Family Environment Scale - Portuguese version]. Unpublished manuscript, Faculdade de Psicologia e de Ciências da Educação, Universidade do Porto, Porto, Portugal.

Missotten, L., Luyckx, K., \& Seiffge-Krenke, I. (2012). Family climate of adolescents with and without type 1 diabetes: Longitudinal associations with psychosocial adaptation. Journal of Child and Family Studies. Advance online publication. doi: 10.1007/s10826$012-9585-1$

Moos, R.H., \& Moos, B.S. (1986). Family Environment Scale Manual (2nd ed.). Palo Alto, CA: Consulting Psychologists Press.

Mullins, L., Fuemmeler, B., Hoff, A., Chaney, J., Pelt, J., \& Ewing, C. (2004). The relationship of parental overprotection and perceived child vulnerability to depressive symptomatology in children with type 1 diabetes mellitus: The moderating influence of parenting stress. Children's Health Care, 33, 21-34. doi: 10.1207/s15326888chc3301_2

Northam, E., Anderson, P., Adler, R., Werther, G., \& Warne, G. (1996). Psychosocial and family functioning in children with insulin-dependent diabetes at diagnosis and one year later. Journal of Pediatric Psychology, 21, 699-717. doi: 10.1093/jpepsy/21.5.699 
FAMILY AND HRQOL IN T1D

Overstreet, S., Goins, J., Chen, R., Holmes, S., Greer, T., Dunlap, W., \& Frentz, J. (1995). Family environment and the interrelation of family structure, child behavior, and metabolic control for children with diabetes. Journal of Pediatric Psychology, 20, $435-$ 447. doi: 10.1093/jpepsy/20.4.435

Pais-Ribeiro, J., Silva, I., Ferreira, T., Martins, A., Meneses, R., \& Baltar, M. (2007).

Validation study of a portuguese version of the hospital anxiety and depression scale. Psychology, Health \& Medicine,12, 225-235. doi:10.1080/13548500500524088

Peterson, C., Schmidt, S., Power, M., Bullinger, M., \& The DISABKIDS Group. (2005). Development and pilot-testing of a health-related quality of life chronic generic module for children and adolescents with chronic health conditions: A European perspective. Quality of Life Research, 14, 1065-1077. doi: 10.1007/s11136-004-2575-z

Preacher, K. J., \& Hayes, A. F. (2008). Asymptotic and resampling strategies for assessing and comparing indirect effects in multiple mediator models. Behavior Research Methods, 40(3), 879-891. doi: 10.3758/BRM.40.3.879

Ravens-Sieberer, U., Erhart, M., Rajmil, L., Herdman, M., Auquier, P., Bruil, J., \& European KIDSCREEN Group (2010). Reliability, construct and criterion validity of the KIDSCREEN-10 score: A short measure for children and adolescents' well-being and health-related quality of life. Quality of Life Research, 19, 1487-1500. doi:10.1007/s11136-010-9706-5

Rentinck, I. C. , Ketelaar, M., Jongmans, M. J., \& Gorter, J. W. (2006). Parents of children with cerebral palsy: A review of factors related to the process of adaptation. Child: Care, Health and Development, 33, 161-169.

Sameroff, A. (1975). Transactional models of early social relations. Human Development, 18, 65-79. doi: $10.1159 / 000271476$ 
FAMILY AND HRQOL IN T1D

Schwarzer, R. \& Leppin, A. (1991). Social support and health: A theoretical and empirical overview. Journal of Social and Personal Relationships, 8, 99-127. doi:

$10.1177 / 0265407591081005$

Shor, E. L. \& American Academy of Pediatrics Task Force on the Family (2003). Family pediatrics: Report of the Task Force on the Family. Pediatrics, 111, 1541-1571.

Small, S., A., Eastman, G., \& Cornelius, S. (1988). Adolescent autonomy and parental stress. Journal of Youth and Adolescence, 17, 377-391. doi: 10.1007/BF01537880

Soliday, E., Kool, E., \& Lande, M. (2001). Family environment, child behavior, and medical indicators in children with kidney disease. Child Psychiatry and Human Development, 31, 279-295. doi: 10.1023/A:1010282305881

Streisand, R., Braniecki, S., Tercyak, K. P., Kazak, A. E. (2001). Childhood illness-related parenting stress: The pediatric inventory for parents. Journal of Pediatric Psychology, 26, 155-162. doi: 10.1093/jpepsy/26.3.155

Streisand, R., Mackey, E., \& Herge, W. (2010). Associations of parent coping, stress, and well-being in mothers of children with diabetes: Examination of data from a national sample. Maternal and Child Health Journal, 14, 612-617. doi: 10.1007/s10995-009-04977

Streisand, R., Swift, E., Wickmark, T., Chen, R., \& Holmes, C. (2005). Pediatric parenting stress among parents of children with type 1 diabetes: The role of self-efficacy, responsibility and fear. Journal of Pediatric Psychology, 30, 513-521. doi: 10.1093/jpepsy/jsi076

Tabachnick, B. G., and Fidell, L. S. (2007). Using multivariate statistics, (5th ed). Boston: Allyn and Bacon.

The European DISABKIDS Group (2006). The DISABKIDS Questionnaires - Quality of Life questionnaires for children with chronic conditions. Lengerich: Pabst Science Publishers. 
FAMILY AND HRQOL IN T1D

Varni, J., Seid, M., \& Kurtin, P. (1999). Pediatric health-related quality of life measurement technology: A guide for health care decisions makers. Journal of Clinical Outcomes Management, 6, 33-40.

Weissberg-Benchell, J., Nansel, T., Holmbeck, G. Chen, R., Anderson, B. Wysocki, T., ...For the Steering Committee of the Family Management of Diabetes Study. (2009).

Generic and diabetes-specific parent-child behaviors and quality of life among youth with type 1 diabetes. Journal of Pediatric Psychology, 34, 977-988. doi:

10.1093/jpepsy/jsp003

Williams, L., Laffel, L., \& Hood, K. (2009). Education and Psychological Aspects Diabetesspecific family conflict and psychological distress in paediatric Type 1 diabetes. Diabetic Medicine, 26, 908-914. doi: 10.1111/j.1464-5491.2009.02794.x

Wysocki, T., Buckloh, L., \& Greco, P. (2009). The psychological context of diabetes mellitus in youths. In M. C. Roberts, \& R. G. Steele (Eds.), Handbook of pediatric psychology (4 ${ }^{\text {th }}$ ed, pp. 287-302). New York: The Guilford Press.

Zigmond, A. P., \& Snaith, R. P. (1983). The Hospital and Depression Scale. Acta Psychiatrica Scandinavica, 67, 361-370. doi:10.1111/j.1600-0447.1983.tb09716.x 
Table 1. Demographic and clinical characteristics of children/adolescents and their parents $(N$ $=209)$

\begin{tabular}{|c|c|c|c|}
\hline & G1 & G2 & \multirow{3}{*}{$F / p$} \\
\hline & $n=88$ & $n=121$ & \\
\hline & $\begin{array}{r}\text { Mean }(S D) ; \text { observed } \\
\text { range }\end{array}$ & $\begin{array}{r}\text { Mean }(S D) ; \text { observed } \\
\text { range }\end{array}$ & \\
\hline Child Age (years) & $13.22(3.12) ; 8-18$ & 12.68 (3.07); 8-18 & $1.55 / .22$ \\
\hline Parents Age (years) & 42.94 (5.55); $29-59$ & 42.34 (5.52); 30-59 & $0.60 / .44$ \\
\hline $\begin{array}{l}\text { Duration of T1DM } \\
\text { (months) }\end{array}$ & 70.04 (46.95); 3-204 & & \\
\hline \multirow[t]{2}{*}{ HbA1c } & 7.59 (1.18); 4.5-10.1 & & \\
\hline & $n(\%)$ & $n(\%)$ & $\mathrm{X}^{2} / p$ \\
\hline \multicolumn{4}{|l|}{ Child gender } \\
\hline Male & $38(43.2)$ & $54(44.6)$ & \multirow{2}{*}{$0.04 / .84$} \\
\hline Female & $50(56.8)$ & $67(55.4)$ & \\
\hline \multicolumn{4}{|l|}{ Parent gender } \\
\hline Male & $7(8.0)$ & $7(5.8)$ & \multirow{2}{*}{$0.38 / .54$} \\
\hline Female & $81(92.0)$ & $114(94.2)$ & \\
\hline \multicolumn{4}{|l|}{ Parent marital status } \\
\hline Single & $1(1.1)$ & $4(3.3)$ & \multirow{5}{*}{$1.69 / .64$} \\
\hline Married/living together & $75(85.2)$ & $104(86.0)$ & \\
\hline Separated/divorced & $9(10.2)$ & $12(9.9)$ & \\
\hline Widowed & $0(0.0)$ & $1(0.8)$ & \\
\hline Missing information & $3(3.4)$ & $0(0.0)$ & \\
\hline \multicolumn{4}{|l|}{ Mensal family income } \\
\hline$<800 €$ & $35(39.8)$ & $39(32.2)$ & \multirow{5}{*}{$6.54 / .09$} \\
\hline $800 €-2000 €$ & $29(33.0)$ & $61(50.4)$ & \\
\hline $2000 €-3500 €$ & $10(11.4)$ & $15(12.4)$ & \\
\hline$>3500 €$ & $6(6.8)$ & $3(2.5)$ & \\
\hline Missing information & $8(9.1)$ & $3(2.5)$ & \\
\hline \multicolumn{4}{|l|}{ Professional status } \\
\hline Employed & $66(75.0)$ & $88(72.7)$ & \multirow{4}{*}{$7.26 / .12$} \\
\hline Unemployed & $11(12.5)$ & $17(14.0)$ & \\
\hline Other & $6(6.8)$ & $12(9.9)$ & \\
\hline Missing information & $5(5.7)$ & $4(3.3)$ & \\
\hline
\end{tabular}


FAMILY AND HRQOL IN T1D

Table 2. Family cohesion, parental adjustment and children's QoL: Comparisons between G1 and G2 (N=209)

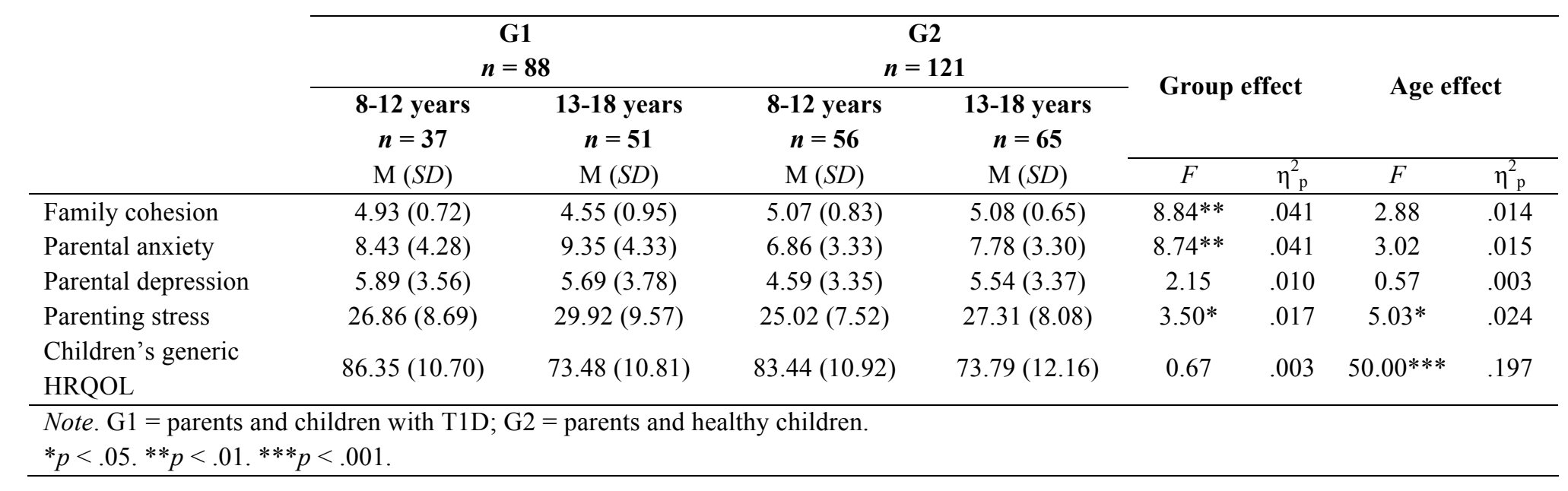


FAMILY AND HRQOL IN T1D

Table 3. Correlations among study variables (G1)

\begin{tabular}{|c|c|c|c|c|c|c|c|c|c|c|}
\hline \multicolumn{2}{|c|}{ Variables } & \multirow{2}{*}{$\frac{1}{---}$} & \multirow[t]{2}{*}{2} & \multirow[t]{2}{*}{3} & \multirow[t]{2}{*}{4} & \multirow[t]{2}{*}{5} & \multirow[t]{2}{*}{6} & \multirow[t]{2}{*}{7} & \multirow[t]{2}{*}{8} & \multirow[t]{2}{*}{9} \\
\hline 1 & Family Cohesion & & & & & & & & & \\
\hline 2 & Parental anxiety & $-.43^{*}$ & & & & & & & & \\
\hline 3 & Parental depression & $-.45^{*}$ & $.74 * *$ & --- & & & & & & \\
\hline 4 & Parenting stress & $-.51 *$ & $.54 * *$ & $.56^{* *}$ & --- & & & & & \\
\hline 5 & Generic HrQOL (Kidscreen) & $.26^{*}$ & $-.29 * *$ & -.20 & $-.26^{*}$ & --- & & & & \\
\hline 6 & General HrQOL & $.24 *$ & $-.38 * *$ & $-.29 * *$ & $-.37 * *$ & $.62 * *$ & --- & & & \\
\hline 7 & Social HrQOL & $.26^{*}$ & $-.33 * *$ & $-.35 * *$ & $-.39 * *$ & $.45^{* *}$ & $.79^{* *}$ & --- & & \\
\hline 8 & Mental HrQOL & $.23 *$ & $-.41 * *$ & $-.23 *$ & $-.32 * *$ & $.62 * *$ & $.96^{* *}$ & $.69 * *$ & --- & \\
\hline 9 & Physical HrQoL & .17 & $-.32 * *$ & $-.23 *$ & $-.32 * *$ & $.56^{* *}$ & $.92 * *$ & $.55^{* *}$ & $.82 * *$ & --- \\
\hline 10 & Children's age & $-.26^{*}$ & .12 & -.01 & .09 & $-.49 * *$ & -.19 & .02 & $-.31 * *$ & -.17 \\
\hline
\end{tabular}


FAMILY AND HRQOL IN T1D

Table 4. Summary of multiple mediation analyses for models including general, mental, social, physical and generic HrQoL (5000 bootstraps).

\begin{tabular}{|c|c|c|c|c|c|c|c|c|}
\hline $\begin{array}{c}\text { Independent } \\
\text { variable }\end{array}$ & $\begin{array}{l}\text { Mediating } \\
\text { variable }\end{array}$ & $\begin{array}{l}\text { Dependent } \\
\text { variable }\end{array}$ & $\begin{array}{c}\text { Effect of IV on } \\
\mathrm{M} \\
b(\mathrm{SE}) \\
\end{array}$ & $\begin{array}{c}\text { Effect of M } \\
\text { on DV } \\
b(\mathrm{SE})\end{array}$ & $\begin{array}{l}\text { Direct effect } \\
b(\mathrm{SE})\end{array}$ & \multicolumn{2}{|c|}{$\begin{array}{l}\text { Indirect effect } \\
b \text { (boot SE) }\end{array}$} & \multirow{2}{*}{$\begin{array}{l}\text { Total effect } \\
b(\mathrm{SE}) \\
\text { (c) }\end{array}$} \\
\hline (IV) & (M) & (DV) & (a) & (b) & $\left(c^{\prime}\right)$ & $(a * b)$ & $\begin{array}{c}95 \% \text { CI } \\
\text { (LLCI; ULCI) }\end{array}$ & \\
\hline \multirow{15}{*}{ Family cohesion } & Parenting stress & & $-5.60(1.10)^{* * *}$ & $-0.38(0.19)^{*}$ & & $2.10(1.01)$ & $0.35 ; 4.38$ & \\
\hline & Parental anxiety & General HrQoL & $-2.09(0.49)^{* * *}$ & $-0.65(0.52)$ & $-0.88(1.98)$ & $1.35(1.30)$ & $-0.70 ; 4.66$ & $2.33(1.71)$ \\
\hline & Parental depression & & $-2.14(0.43)^{* * *}$ & $-0.11(0.59)$ & & $0.25(1.14)$ & $-2.99 ; 1.73$ & \\
\hline & Parenting stress & & $-5.60(1.10)^{* * *}$ & $-1.45(0.95)$ & & $8.11(4.52)$ & $-0.15 ; 17.90$ & \\
\hline & Parental anxiety & Mental HrQoL & $-2.09(0.49) * * *$ & $-3.28(2.62)$ & $-0.96(10.03)$ & $6.84(6.24)$ & $-3.01 ; 22.78$ & $11.21(8.48)$ \\
\hline & Parental depression & & $-2.14(0.43)^{* * *}$ & $-1.31(2.99)$ & & $2.79(5.44)$ & $-16.17 ; 5.98$ & \\
\hline & Parenting stress & & $-5.60(1.10)^{* * *}$ & $-1.02(0.57)^{*}$ & & $5.70(3.01)$ & $0.35 ; 12.33$ & \\
\hline & Parental anxiety & Social HrQoL & $-2.09(0.49)^{* * *}$ & $-1.55(1.59)$ & $-2.18(6.07)$ & $3.23(4.03)$ & $-2.67 ; 13.21$ & $8.50(5.26)$ \\
\hline & Parental depression & & $-2.14(0.43)^{* * *}$ & $-0.82(1.81)$ & & $1.74(4.16)$ & $-7.58 ; 9.00$ & \\
\hline & Parenting stress & & $-5.60(1.10)^{* * *}$ & $-2.04(1.01)^{*}$ & & $11.44(6.08)$ & $1.34 ; 25.56$ & \\
\hline & Parental anxiety & Physical HrQoL & $-2.09(0.49) * * *$ & $-2.88(2.80)$ & $-7.41(10.71)$ & $6.00(6.77)$ & $-5.60 ; 21.90$ & $8.24(9.17)$ \\
\hline & Parental depression & & $-2.14(0.43)^{* * *}$ & $-0.84(3.19)$ & & $1.79(6.23)$ & $-15.93 ; 9.63$ & \\
\hline & Parenting stress & & $-5.60(1.10)^{* * *}$ & $-.14(.18)$ & & $.80(.96)$ & $-1.03 ; 2.85$ & \\
\hline & Parental anxiety & $\begin{array}{l}\text { Generic HrQOL } \\
\text { (Kidscreen) }\end{array}$ & $-2.09(0.49)^{* * *}$ & $-.91(.50)$ & $1.65(1.91)$ & 1.85 (1.17) & $-.18 ; 4.58$ & $3.39(1.60)$ \\
\hline & Parental depression & & $-2.14(0.43)^{* * *}$ & $-.43(.57)$ & & $.92(1.27)$ & $-3.97 ; 1.23$ & \\
\hline
\end{tabular}


Figure 1. Moderated mediation model

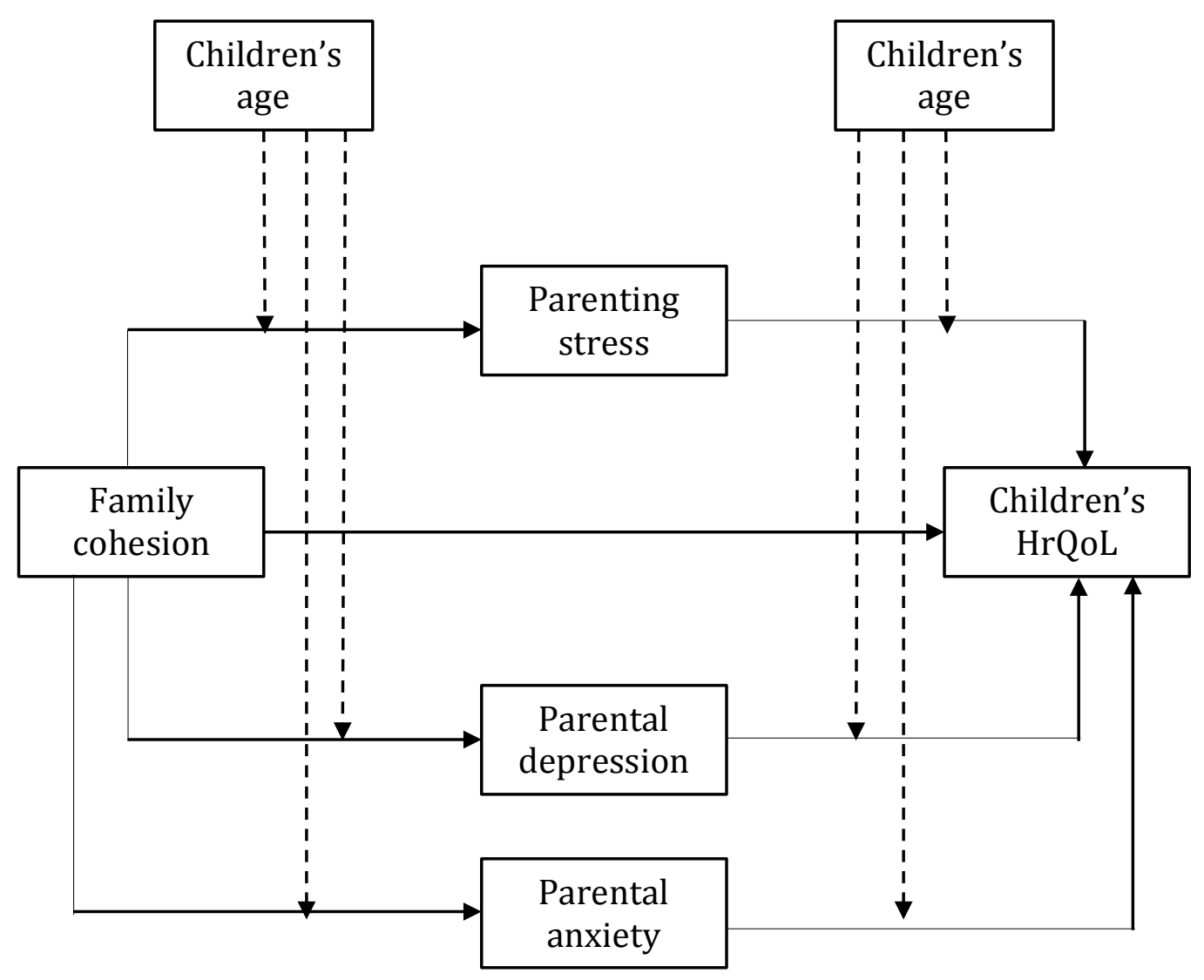

